\title{
The Relationship Between Federal Housing Assistance and Uptake of Cancer Screening Among Low-Income Adults
}

\author{
Michelle S. Wong, $P h D^{7}$, Carolyn M. Arnold, $M D M P H^{2}$, Eric T. Roberts, $P h D^{3}$, and \\ Craig E. Pollack, MD MHS
}

'VA HSR\&D Center for the Study of Healthcare Innovation, Implementation, \& Policy (CSHIIP), Los Angeles, CA, USA; ${ }^{2}$ Boston Medical Center, Boston, MA, USA; ${ }^{3}$ School of Public Health, University of Pittsburgh, Pittsburgh, PA, USA; ${ }^{4}$ School of Medicine and Bloomberg School of Public Health, Johns Hopkins University, Baltimore, MD, USA.

J Gen Intern Med 34(12):2714-6

DOI: $10.1007 /$ s11606-019-05037-Z

(C) Society of General Internal Medicine (This is a U.S. government work and not under copyright protection in the U.S.; foreign copyright protection may apply) 2019

\section{INTRODUCTION}

Lower rates of cancer screening among racial/ethnic minorities and low-income populations may contribute to disparate cancer outcomes. ${ }^{1}$ Federal housing assistance programs may potentially influence cancer screening disparities but has received relatively little attention. These programs, which are administered through the U.S. Department of Housing and Urban Development (HUD) and include public housing and rental assistance (i.e., Housing Choice Vouchers), currently serve approximately 10 million individuals. ${ }^{2}$ Similar to populations in the USA with the lowest cancer screening rates, HUD housing assistance recipients are nearly exclusively low-income and disproportionately nonwhite. ${ }^{3}$ Federal housing assistance may affect cancer screening rates through several mechanisms. For example, housing assistance programs may increase household financial resources through rental subsidies, improve healthcare access by collocating housing with health centers and social services, and change the residential neighborhood context. ${ }^{3,4}$ The primary aim of this study was to examine the relationship between participation in federal housing assistance programs and self-reported cancer screening among low-income adults.

\section{METHODS}

We used 2004-2012 data from the National Health Interview Survey (NHIS), a nationally representative, cross-sectional survey, linked with 2004-2012 HUD administrative data (for

Carolyn M. Arnold is the co-first author

Electronic supplementary material The online version of this article (https://doi.org/10.1007/s11606-019-05037-z) contains supplementary material, which is available to authorized users.

Received April 9, 2019

Accepted April 11, 2019

Published online June 13, 2019 housing assistance status) and the 2007-2011 American Community Survey 5-year estimate files (for neighborhood characteristics information). ${ }^{5}$ We limited the analysis to individuals in low-income households $(<250 \%$ the income-to-poverty ratio) without a prior diagnosis of the cancer of interest. Our primary exposure was the receipt of housing assistance at the time of the NHIS. To help address potential confounding, we constructed two comparison groups: (1) a "quasi-waitlist" group who was not currently receiving housing assistance at the time of the survey but who would go on to receive housing assistance within 2 years (the average housing assistance waitlist time) ${ }^{4}$ and (2) a propensity score-weighted group constructed using inverse probability weights. Our outcomes were the receipt of colorectal (men and women ages 50 to 75), breast (women ages 40 to 74), and cervical cancer screening (women ages 21 to 65 ) in the past 12 months. We constructed separate logistic regression models for each cancer type, employing a doubly robust model for our propensity score-weighted group, accounting for individual and neighborhood characteristics (Table 1), and incorporating the NHIS survey weights.

\section{RESULTS}

In the quasi-waitlist approach, there were 1394 individuals eligible for colorectal cancer (CRC) screening, 1251 for breast cancer screening, and 2028 individuals for cervical cancer screening. Overall, the proportion of non-Hispanic Black adults ranged from 23.3 to $43.8 \%$ across cancer screening types and receipt of housing assistance; around one-third of participants had at least some college (32.2-34.6\%); and approximately half had Medicaid coverage (52.0-56.8\%). Current and quasi-waitlist housing assistance groups were similar with few exceptions. The propensity score analysis yielded larger samples (CRC 15,594 adults; breast cancer 12,398 women; cervical cancer 21,216 women) with appropriate balance on observable covariates.

Overall, in the quasi-waitlist comparisons, $22.4 \%$ of adults reported receiving CRC screening, $63.6 \%$ of women for breast cancer, and $69.8 \%$ of women for cervical cancer, in the past 12 months. Proportions were similar in both the current and 
Table 1 Quasi-Waitlist Sample Characteristics for Each Screening Subpopulation Stratified by Housing Assistance Status

\begin{tabular}{|c|c|c|c|c|c|c|c|c|c|}
\hline & \multicolumn{3}{|c|}{$\begin{array}{l}\text { Colorectal cancer screening } \\
N=1384\end{array}$} & \multicolumn{3}{|c|}{$\begin{array}{l}\text { Breast cancer screening } \\
N=1251\end{array}$} & \multicolumn{3}{|c|}{$\begin{array}{l}\text { Cervical cancer screening } \\
N=\mathbf{2 0 2 8}\end{array}$} \\
\hline & $\begin{array}{l}\text { Current } \\
n=1199\end{array}$ & $\begin{array}{l}\text { Future } \\
n=195\end{array}$ & $p$ value & $\begin{array}{l}\text { Current } \\
n=1083\end{array}$ & $\begin{array}{l}\text { Future } \\
n=168\end{array}$ & $p$ value & $\begin{array}{l}\text { Current } \\
n=1729\end{array}$ & $\begin{array}{l}\text { Future } \\
n=299\end{array}$ & $p$ value \\
\hline Cancer screening & 21.2 & 26.0 & 0.581 & 62.3 & 67.7 & 0.653 & 70.7 & 67.1 & 0.655 \\
\hline Age (mean, SD) & $61.6(9.4)$ & $62.5(9.9)$ & 0.576 & $56.5(13.0)$ & $55.1(13.3)$ & 0.552 & $40.0(17.1)$ & $37.5(14.4)$ & 0.089 \\
\hline \multicolumn{10}{|l|}{ Sex } \\
\hline Male & 26.8 & 28.6 & 0.821 & 0 & 0 & - & 0 & 0 & - \\
\hline \multicolumn{10}{|l|}{ Race/ethnicity } \\
\hline NH White & 54.5 & 50.7 & \multirow[t]{4}{*}{0.782} & 44.3 & 44.1 & \multirow[t]{4}{*}{0.806} & 25.6 & 37.5 & \multirow[t]{4}{*}{0.173} \\
\hline NH Black & 23.1 & 23.6 & & 24.8 & 32.1 & & 44.5 & 41.8 & \\
\hline Hispanic & 14.8 & 12.4 & & 14.8 & 11.0 & & 19.4 & 20.7 & \\
\hline $\mathrm{NH}$ other & 7.6 & 13.3 & & 16.0 & 12.8 & & 10.6 & 0 & \\
\hline \multicolumn{10}{|l|}{ Marital status } \\
\hline Single/never married & 18.1 & 17.1 & \multirow[t]{3}{*}{0.372} & 21.2 & 21.8 & \multirow[t]{3}{*}{0.877} & 55.4 & 41.4 & \multirow[t]{3}{*}{0.227} \\
\hline Married & 13.3 & 24.7 & & 18.9 & 23.1 & & 14.0 & 22.4 & \\
\hline Widowed, divorced, separated & 68.7 & 58.3 & & 59.9 & 55.1 & & 30.7 & 36.2 & \\
\hline \multicolumn{10}{|c|}{ Highest level of family educational attainment } \\
\hline Less than high school & 39.0 & 27.7 & \multirow[t]{3}{*}{0.024} & 33.3 & 30.9 & \multirow[t]{3}{*}{0.775} & 29.0 & 24.6 & \multirow[t]{3}{*}{0.476} \\
\hline Completed high school/GED & 25.3 & 49.8 & & 31.1 & 37.7 & & 35.1 & 44.8 & \\
\hline At least some college & 35.7 & 22.5 & & 35.6 & 31.3 & & 35.9 & 30.6 & \\
\hline \multicolumn{10}{|l|}{ Employment status } \\
\hline Employed & 17.0 & 24.1 & \multirow[t]{3}{*}{0.212} & 25.2 & 40.1 & \multirow[t]{3}{*}{0.037} & 57.9 & 67.6 & \multirow[t]{3}{*}{0.401} \\
\hline Unemployed & 71.8 & 55.0 & & 62.5 & 34.7 & & 33.6 & 22.7 & \\
\hline Out of workforce/retired & 11.2 & 20.9 & & 12.3 & 25.3 & & 8.4 & 9.8 & \\
\hline Family income-to-poverty ratio & & & & & & & & & \\
\hline$<0.50$ & 6.5 & 3.5 & 0.620 & 10.6 & 7.2 & 0.502 & 27.4 & 18.1 & 0.268 \\
\hline $0.50-0.99$ & 50.9 & 50.8 & & 48.3 & 47.3 & & 47.3 & 39.6 & \\
\hline $1.00-1.49$ & 33.2 & 36.2 & & 28.0 & 34.0 & & 115.3 & 20.3 & \\
\hline $1.50-1.99$ & 6.2 & 9.5 & & 6.7 & 11.5 & & 5.1 & 11.5 & \\
\hline $2.00-2.49$ & 3.2 & 0 & & 6.4 & 0 & & 4.9 & 10.5 & \\
\hline Insurance coverage* & & & & & & & & & \\
\hline Private insurance & 13.3 & 14.8 & 0.832 & 18.2 & 25.4 & 0.422 & 16.6 & 13.4 & 0.621 \\
\hline Medicaid & 50.8 & 67.7 & 0.101 & 54.8 & 62.5 & 0.491 & 53.2 & 48.5 & 0.628 \\
\hline Medicare & 55.2 & 9.6 & 0.771 & 40.6 & 38.3 & 0.828 & 9.9 & 9.9 & 0.861 \\
\hline No coverage & 15.0 & 9.6 & 0.426 & 15.8 & 14.6 & 0.864 & 24.4 & 35.1 & 0.206 \\
\hline $\begin{array}{l}\text { Mortality risk index (mean, } \\
\text { SD) } \dagger\end{array}$ & $8.6(5.7)$ & $8.0(5.9)$ & 0.469 & $7.6(5.1)$ & $6.4(5.2)$ & 0.191 & N/A & & \\
\hline Self-rated health & & & & & & & & & \\
\hline Excellent/very good & N/A & & & & & & 35.3 & 53.1 & 0.398 \\
\hline Good/fair/poor & & & & & & & 64.7 & 46.9 & \\
\hline Region & & & & & & & & & \\
\hline Northeast & 28.5 & 24.8 & 0.868 & 27.2 & 14.0 & 0.027 & 18.0 & 10.8 & 0.163 \\
\hline Midwest & 21.4 & 20.9 & & 31.1 & 16.4 & & 25.1 & 19.5 & \\
\hline South & 29.7 & 35.0 & & 24.1 & 38.6 & & 37.2 & 54.9 & \\
\hline West & 20.5 & 19.3 & & 17.5 & 31.1 & & 19.7 & 14.7 & \\
\hline Neighborhood deprivation quartil & & & & & & & & & \\
\hline Quartile 1 (highest deprivation) & 28.1 & 15.3 & 0.452 & 11.5 & 22.3 & 0.421 & 11.4 & 26.3 & 0.041 \\
\hline Quartile 2 & 22.7 & 21.3 & & 25.6 & 29.6 & & 20.2 & 9.2 & \\
\hline Quartile 3 & 24.6 & 33.5 & & 25.8 & 20.1 & & 30.1 & 23.0 & \\
\hline Quartile 4 & 24.6 & 29.9 & & 37.1 & 28.0 & & 41.5 & 38.3 & \\
\hline
\end{tabular}

Italicize entries denote statistically significant differences between the current and future housing assistance groups at $p<0.05$

*Insurance coverage categories are not mutually exclusive as respondents can report multiple types of coverage at time of survey. Proportions represent anyone who indicated having that source of insurance coverage

$\uparrow$ Mortality risk score 6 predicts 5-year mortality among older adults. We calculated and adjusted for this in the colorectal and breast cancer screening samples, but not for the cervical cancer as that sample is younger. Instead, we calculated and adjusted for self-rated health for the cervical cancer sample

$\$$ Neighborhood deprivation calculated from six U.S. Census measures in the American Community Survey data identified through a factor analysis: \% of residents with less than a high school education; \% of residents with less than a 4-year college degree, unemployment rate, poverty rate; $\%$ of working residents in a non-management (primary) occupation, and the vacancy rate of housing units

quasi-waitlist housing assistance groups. After adjustment for potential confounders, receipt of housing assistance was not associated with a significantly higher odds of cancer screening compared to the quasi-waitlist or propensity score-weighted groups (Fig. 1). Associations between housing assistance and cancer screening remained non-significant in sensitivity analyses in which we (a) included those with a prior cancer diagnosis and (b) used guideline-concordant screening intervals (available for a subset of NHIS years).

\section{DISCUSSION}

As clinicians and policymakers attempt to address the known racial/ethnic and socioeconomic disparities in cancer mortality, it is important to examine social determinants of health like federal housing assistance that may influence these efforts. Our findings from a cross-sectional study with nationally representative survey data reinforce the need to improve rates of screening and suggest that providing housing assistance, in 


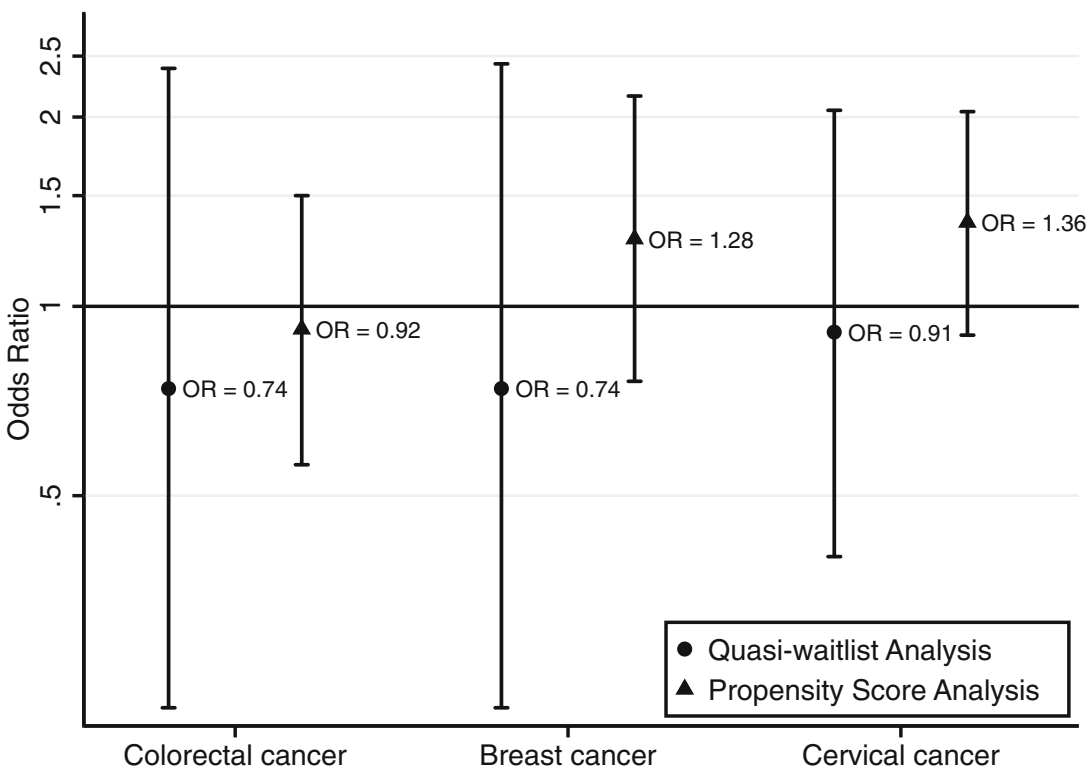

Fig. 1 Adjusted odds ratios of the associations between receipt of cancer screening in the past 12 months and housing assistance. Models adjusted for the following: colorectal cancer: sex, age, race/ethnicity, marital status, employment status, insurance status, education, income, mortality index, year, region, year-by-region interactions, and neighborhood SES; breast cancer: age, race/ethnicity, marital status, employment status, insurance status, education, income, mortality index, year, region, year-by-region interactions, and neighborhood SES; and cervical cancer: age, race/ethnicity, marital status, employment status, insurance status, education, income, self-rated health, year, region, year-byregion interactions, and neighborhood SE.

and of itself, may be insufficient to overcome the multiple access barriers that low-income populations face. Other psychosocial, clinically related, and structural barriers to preventive services should be considered in improving cancer screening for low-income adults. As housing authorities, developers, and health systems work to use housing as a platform for service coordination and health promotion, greater attention should be given to improving cancer screening in this vulnerable population.

Acknowledgments: We would like to thank Patricia Barnes, analyst at the U.S. Center for Disease Control and Prevention's National Center for Health Statistics, and Veronica Helms, analyst in the U.S. Department of Housing and Urban Development, for their partnership and guidance on this project.

Dr. Wong was supported by the VA Office of Academic Affiliation through the Health Services Research fellowship, the Agency for Healthcare Research and Quality (Award Number T32HSOOOO29), and National Institute of Diabetes and Digestive and Kidney Diseases of the National Institutes of Health (Award Number T32DK062707).

Corresponding Author: Craig E. Pollack, MD MHS; School of Medicine and Bloomberg School of Public Health Johns Hopkins University, Baltimore, MD, USA (e-mail: cpollac2@jhu.edu).

\section{Compliance with Ethical Standards:}

Conflict of Interest: The authors declare that they do not have a conflict of interest.
Disclaimer: The content is solely the responsibility of the authors and does not necessarily represent the official views of the U.S. Department of Veterans Affairs or the United States Government, the National Institutes of Health, or Agency for Healthcare Research and Quality.

\section{REFERENCES}

1. Lansdorp-Vogelaar I, Kuntz KM, Knudsen AB, van Ballegooijen $\mathbf{M}$, Zauber AG, Jemal A. Contribution of screening and survival differences to racial disparities in colorectal cancer rates. Cancer Epidemiol Biomarkers Prev. 2012;21(5):728-736. https://doi.org/10.1158/1055-9965.EPI-120023

2. Congressional Budget Office. Federal housing assistance for low-income households; 2015. https://doi.org/10.1126/science.23.597.887-a

3. U.S. Department of Housing and Urban Development Office of Policy Development and Research. USHMC 95: Public Housing: Image Versus Facts. https://www.huduser.gov/periodicals/ushmc/spring95/spring95. html. Accessed 3 April 2019.

4. Simon AE, Fenelon A, Helms V, Lloyd PC, Rossen LM. HUD housing assistance associated with lower uninsurance rates and unmet medical need. Health Aff. 2017;36(6): 1016-1023. https://doi.org/10.1377/hlthaff. 2016. 1152

5. Lloyd PC, Helms VE. NCHS-HUD linked data: analytic considerations and guidelines. Hyattsville, 2016.

6. Schonberg MA, Davis RB, McCarthy EP, Marcantonio ER. Index to predict 5-year mortality of community-dwelling adults aged 65 and older using data from the National Health Interview Survey. J Gen Intern Med. 2009;24(10):1115-1122. https://doi.org/10.1007/s11606-009-1073-y

Publisher's Note Springer Nature remains neutral with regard to jurisdictional claims in published maps and institutional affiliations. 